\title{
Health Promotion Program of Yoga Exercise among Female in Workplace
}

\author{
Su Ying Tsai* \\ *Department of Health Management, I-Shou University, Taiwan
}

Submission: September 20, 2017; Published: September 21, 2017

*Corresponding author: Su Ying Tsai, Department of Health Management, I-Shou University, Kaohsiung, Taiwan No.8, Yida Rd., Yanchao Township, Kaohsiung Country 824, Taiwan (R.O.C.), Tel: 8867-615-1100; Fax: 8867-615-5150; Email: sytsai@isu.edu.tw

\section{Introduction}

Working women are a larger part of workforce than in previous generations. Premenstrual syndrome (PMS) is a common disorder in menstruating females. All women, regardless of race, age, or socioeconomic status, have experienced discomfort during their menstrual periods. Painful menstrual periods or PMS are the most common gynecologic problems as well as the most common reason for increased absenteeism and more workdays with $50 \%$ or less of typical productivity per month in female employees [1]. Females with PMS report a poorer perceived quality of sleep [2] and health-related quality of life [3-5], and PMS may result in a depressed mood and greater psychiatric comorbidity [6]. Severe menstrual symptoms lead to increased healthcare utilization, decreased occupational productivity, and absence from work [7].

In recent years, with the rise of educational level and social changes, female labor force has become an indispensable stable foundation for economic development in Taiwan. To our knowledge, when female workers have PMS in the workplace in Taiwan, care personnel in the workplace usually provide heat packs or suggest bed rest at a health center or may provide painkillers. These methods, which merely alleviate female workers' pain at the time the menstrual cramps occur, are not preventive methods. Recent studies reported an association between exercise and PMS and indicated that a regular exercise habit might be associated with a decrease in some physical and psychologic premenstrual symptoms [8-9]. Exercise is commonly listed as a remedy for PMS. Hence, more and more workplaces and employers are attempting to determine preventive methods or health promotion activities that can ameliorate PMS in female workers during their menstrual periods.

A growing body of evidence indicates that yoga benefits physical and mental health by down regulating the hypothalamic-pituitaryadrenal axis and the sympathetic nervous system [10]. Yoga is a mind and body practice with historical origins in ancient Indian philosophy. Many clinicians treating persistent pain hear about the benefits of yoga from patients who frequent yoga centers. Yoga classes specifically designed for women with PMS have increased, but there is little research about the efficacy of these classes. No research in Taiwan has addressed improvement or changes in female workers' menstrual discomfort through interventional psychologic and physical yoga activities in the workplace. The research setting was Company $\mathrm{C}$, a large electronics manufacturer requiring highly labor-intensive work in the Tainan Science Park in Southern Taiwan. This company has many female employees of reproductive age, the director of health management pay attention to female employees' premenstrual disorders and the negative impact of premenstrual symptoms on occupational productivity and attendance. The yoga exercise program was 12 weeks long and featured physically and psychologically interventional yoga activities to determine changes in female workers' menstrual discomfort.

This study invited all eligible employees (female employees aged 20 to 45 years who were healthy premenopausal women, taking no oral contraceptives, and taking no medication during the last 3 months) and all of them voluntarily participated in this program. Written and signed informed consent was obtained from each participant. The yoga teacher personally guided each participant's yoga exercise activities at twice-aweek 50-min sessions after work in the plant's fitness center. There were four yoga classes a week to choose from, allowing participants to select the most convenient time to participate in two yoga classes per week. Each 50-min session comprised a 5-min breathing exercise, 35-min yoga pose practice, and 10-min supine meditation/relaxation. Before starting the yoga exercise intervention programs, we administered a structured self- report questionnaire to the participants to collect information about baseline menstrual pain scores, premenstrual symptoms, and health-related quality of life during the prior 6 months. At the end of the 12-week yoga exercise intervention, we administered the same questionnaire to evaluate changes in the participants' menstrual discomfort. 
A total of 64 participants completed the intervention study. Data revealed that moderate or severe effect of menstrual pain on work was reported by $53.1 \%$ participants, with $35.9 \%$ subjects reporting the need for analgesics every month during menstruation to relieve menstrual pain. The comparison of characteristics of menstruation before the yoga exercise intervention and after 3 months revealed that $14 \%$ participants significantly decreased their use of analgesics during menstruation and the prevalence of a moderate or severe effect of menstrual pain on work significantly declined $23.4 \%$ after the yoga exercise intervention. Menstrual pain scores above 80 were reported by $14.1 \%$ subjects before the intervention, but after 12 weeks of yoga exercise the prevalence decreased to only $4.7 \%$ of subjects. The 12 -week yoga exercise intervention was significantly correlated with decreased prevalence of four physical symptoms, including abdominal swelling, breast tenderness, abdominal cramps, and cold sweats.

Based on this data, these findings suggest that yoga exercise in the workplace effectively reduces the symptoms of PMS and can be applied to other woman-friendly workplaces to relief PMS. The results will contribute to our understanding of the current status of a menstrual health-friendly workplace environment for female employees and can be used to establish a model for a healthy lifestyle with a regular yoga exercise to decrease the negative impact of premenstrual symptoms. However, this program has some limitations [11]. Nevertheless, workplaces and employers can help female employees to understand the benefits of regular exercise, such as yoga, which may decrease premenstrual distress and improve the health of female employees. This program may be able to provide a reference for menstrual health promotion of female employees in the future workplace.

\section{References}

1. Dean BB, Borenstein JE (2004) A prospective assessment investigating the relationship between work productivity and impairment with premenstrual syndrome. J Occup Environ Med 46(7): 649-656.

2. Borenstein JE, Dean BB, Endicott J, Wong J, Brown C, et al. (2003) Health and economic impact of the premenstrual syndrome. J Reprod Med 48(7): 515-524.

3. Freeman EW (2003) Premenstrual syndrome and premenstrual dysphoric disorder: definitions and diagnosis. Psychoneuroendocrinology 28(Suppl 3): 25-37.

4. Qiao M, Zhang H, Liu H, Luo S, Wang T, et al. (2012) Prevalence of premenstrual syndrome and premenstrual dysphoric disorder in a population-based sample in China. Eur J Obstet Gynecol Reprod Biol 162(1): 83-86.

5. Tschudin S, Bertea PC, Zemp E (2010) Prevalence and predictors of premenstrual syndrome and premenstrual dysphoric disorder in a population-based sample. Arch Womens Ment Health 13(6): 485-494.

6. Takeda TI, Tasaka K, Sakata M, Murata Y (2006) Prevalence of premenstrual syndrome and premenstrual dysphoric disorder in Japanese women. Arch Womens Ment Health 9(4): 209-212.

7. Baker FC, Kahan TL, Trinder J, Colrain IM (2007) Sleep quality and the sleep electroencephalogram in women with severe premenstrual syndrome. Sleep 30(10): 1283-1291.

8. Samadi Z, Taghian F, Valiani M (2013 The effects of 8 weeks of regular aerobic exercise on the symptoms of premenstrual syndrome in nonathlete girls. Iran J Nurs Midwifery Res 18(1): 14-19.

9. Wu WL, Lin TY, Chu IH, Liang JM (2015) The acute effects of yoga on cognitive measures for women with premenstrual syndrome. J Altern Complement Med 21(6): 364-369.

10. Bertone Johnson ER, Hankinson SE, Johnson SR, Manson JE (2008) Cigarette smoking and the development of premenstrual syndrome. Am J Epidemiol 168(8): 938-945.

11. Tsai SY (2016) Effect of yoga exercise on premenstrual symptoms among female employees in Taiwan. Int J Environ Res Public Health 13(7).

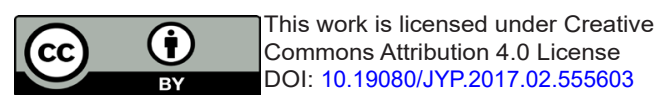

\section{Your next submission with Juniper Publishers will reach you the below assets}

- Quality Editorial service

- Swift Peer Review

- Reprints availability

- E-prints Service

- Manuscript Podcast for convenient understanding

- Global attainment for your research

- Manuscript accessibility in different formats ( Pdf, E-pub, Full Text, Audio)

- Unceasing customer service

Track the below URL for one-step submission

https://juniperpublishers.com/online-submission.php 